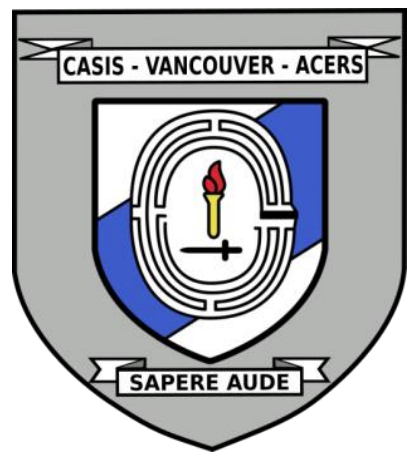

\title{
REIMAGINING A CANADIAN NATIONAL SECURITY STRATEGY
}

Date: November 26, 2021

Disclaimer: This briefing note contains the encapsulation of views presented by the speaker and does not exclusively represent the views of the Canadian Association for Security and Intelligence Studies.

\section{KEY EVENTS}

On November 26, 2021, Mr. Aaron Shull, Managing Director and General Counsel at the Centre for International Governance Innovation (CIGI), presented on Reimaging a Canadian National Security Strategy at the 2021 CASIS West Coast Security Conference. The presentation was followed by a question and answer period with questions from the audience and CASIS Vancouver executives. The key points discussed included CIGI's new project to address Canada's national security strategy gap and what it will take to accomplish the goals that could derive from the recommendations provided.

\section{NATURE OF DISCUSSION}

\section{Presentation}

Mr. Shull's presentation focused on the process and highlights of CIGI's new project aiming to help build a new national strategy in the face of emerging threats, considering Canada's out-of-date national security strategy. Mr. Shull also discussed some of the recommendations made to better national security.

\section{Question Period}

The question period touched upon the reasons CIGI's project opted to stay away from the subject of extremism and what is needed to accomplish the goals derived from CIGI's recommendations to address national security strategies. 


\section{BACKGROUND}

\section{Presentation}

Mr. Shull began his presentation by discussing how CIGI has found a critical gap in Canada's national security strategy and put together a group to reimagine what a Canadian national security strategy could look like. Early national security focused on protecting the land, sea, and air borders from foreign threats; however, with a new era of telecommunications and computers ushering in new ways to gather intelligence, non-state actors can be just as much of a threat as nationstates in the modern world. Mr. Shull stated that national security is interconnected to more than just borders, the threat of war, and espionage. There are also pandemics, biosecurity, climate change, intellectual property theft, and data governance which add new dimensions of national security.

Mr. Shull emphasized that Canada is facing a new and extremely challenging national security threat environment, unlike anything we have ever experienced before. Readiness to understand and respond to this environment, with its many complex dimensions, must be strengthened as a national priority. Some of these emerging threats include climate change, technological change, pandemics, economic security, and geopolitical disruption.

At the beginning of fall 2020, CIGI put together a diverse group that included 250 Canadian and international experts from the government, academia, the commercial sector, and civil society to help devise a new national security strategy that accounts for these new dimensions. This process included 65 working meeting groups, 21 senior government liaisons, 17 theme leads, and 4 project advisors. Prior to starting this project, however, CIGI reached out to various policy makers and government sectors to ensure the support of key officials and that project itself could be useful. By creating a national conversation about this issue, they could see the positive outcomes that would originate from such a project.

In the various working groups, CIGI had experts in each of the ten thematic areas to lead the discussion for each meeting. The ten thematic areas of focus included:

- A new approach to Canadian national security

- Rethinking intelligence

- Making digital living safe and secure

- Emerging technologies, game changers, and impacts on national security

- Economic security and a changing global economy

The Journal of Intelligence, Conflict, and Warfare Volume 4, Issue 3 
- Mitigating climate change security impacts

- After COVID: pandemics and biosecurity strategy

- Borders and the new geopolitics

- Ensuring democracy

- International Security: Canada's role in meeting global threats

In each of these meetings, CIGI included individuals who were not necessarily associated with the national security apparatus in order to offer diverse perspectives, as well as senior government liaisons to ensure they were approaching the issue in a meaningful way.

The objectives of this project were to reach multiple audiences and provide new perspectives to policymakers on complex national security issues, increase Canadians' understanding about national security discourse, and recognize the need for a new strategic approach. Mr. Shull stated that it is time for Canada to engage with and educate the public on national security issues.

Mr. Shull also noted that this project will be successful if they are able to establish new relationships between this network of stakeholders, foster innovative ideas, inspire the formation of new networks, and sensitize public opinion around the various issues we are dealing with. Mr. Shull pointed out they would release a special report on December 6, 2021, highlighting the details of these recommendations. The five large categories surrounding these recommendations include strategic review, decision-making and governance, legislative amendments, transparency around public reporting, and engagement and capacity building.

Mr. Shull concluded his presentation by reiterating that an inclusive public conversation and agenda changes are long overdue. There is also a need to adjust the current policies and respond to these new circumstances surrounding national security if the government is to combat emerging threats effectively.

\section{Question Period}

During the question and answer period, the audience asked Mr. Shull how reimagining Canada's national security policy project addresses threats such as right-wing extremism or information operations that can fall under multiple departments or agencies. Mr. Shull noted that when considering threats that fall under different agencies, we tend to think in bureaucratic terms or in operational silos. However, adversarial states think strategically, using every lever of state power; therefore, according to Mr. Shull, we need to think the same way. Mr.

The Journal of Intelligence, Conflict, and Warfare Volume 4, Issue 3 
Shull also noted that domestic extremism is a law enforcement issue with a national security element. Because of this, CIGI opted to stay away from it. However, in their project, they also discussed protecting democratic institutions from foreign interference, as well as the cyber elements and emerging tech such as quantum-safe computing; amped up artificial intelligence (AI); and adversarial AI and datasets. Mr. Shull emphasized that these issues need to be seen as interconnected and not as separate issues. This can allow Canada to be on the same playing field as its adversaries.

When asked whether there was sufficient will or resources for Canadian policymakers to achieve the goals of CIGI's project, Mr. Shull noted that this question exposed a nuance because the is no natural "national security" constituency or voting bloc, leaving a clear path for potential risk and exposure. Mr. Shull also indicated that this is going to take political will, which is often not easy to accomplish, and it will test true leadership.

\section{KEY POINTS OF DISCUSSION}

\section{Presentation}

- Non-state actors can be just as much of a threat as nation-states in the modern world.

- National security is interconnected to more than just borders, the threat of war, and espionage; pandemics, biosecurity, climate change, intellectual property theft, and data governance add new dimensions to national security.

- CIGI's objective is to reach multiple audiences and provide new perspectives to policymakers on complex national security issues and ensure they recognize the need for a new strategic approach, as well as to increase Canadians' understanding about national security discourse.

- The top five categories surrounding CIGI's recommendations include strategic review, decision-making and governance, legislative amendments, transparency around public reporting, and engagement and capacity building.

- Inclusive public conversation and agenda changes are long overdue in terms of national security; hence the need to change our policies and respond to these new circumstances surrounding national security.

\section{Question Period}

- When it comes to threats that fall under multiple agencies, we tend to think in bureaucratic terms or in operational silos. Adversarial states think 
strategically using every lever of state power; thus, Canada needs to do the same.

- Domestic extremism is a law enforcement issue with a national security element.

- The success of this project will depend on the political will as well as perseverance of true leadership.

(c) $($ ) $(9)$

Commercial-NoDerivatives 4.0 International License.

(C) (AARON SHULL, 2022)

Published by the Journal of Intelligence, Conflict, and Warfare and Simon Fraser University

Available from: https://jicw.org/

The Journal of Intelligence, Conflict, and Warfare

Volume 4, Issue 3 